(C) A. Мажиа

\title{
ЯЗЫКОВАЯ ИДЕНТИЧНОСТЬ И ЯЗЫКИ ИДЕНТИЧНОСТИ (НА ПРИМЕРЕ ОСТРОВА САРДИНИЯ, ИТАЛИЯ)*
}

\begin{abstract}
Цель исследования - расшифровать механизмы авторепрезентации идентичности жителями Сардинии и, соответственно, выявить скрытые в данном понятии функции. Фокус особого внимания сосредоточен на сардинском языке. Через посредство этого идиома предпринята попытка обнажить механизмы искусственного конструирования идентичности. Конкретнее - в статье представлень актуальные концепции и интерпретаџии сардинской идентичности, анализируется ее взаимосвязь с местным языком. Работа основана на результатах этнологического исследования, проведенного в одном из регионов внутренней Сардинии в 2019-2020 г2. Материал собирался методом интервьюирования сардинцев и включенного наблюдения в их среде. Были получены и затем проанализированы сведения, отражающие состояние сардинского языка, уровень его сохранности и особенности использования населением острова в различных сферах жизни. Автор сравнивает данные, полученные в ходе собственного полевого исследования, с фактами двух более ранних масштабных исследований: сочиолингвистического опроса, проведенного в 2007 г. в Сардинии сотрудниками университетов Кальяри и Сассари, а также с итоговыми результатами мега-опроса по миноритарным языкам, осуществленного Европейским Союзом в 1996 г. во многих странах, в том числе и в Италии. Сравнительно-сопоставительный подход с использованием данных разных лет позволяет оценить культурные и сочиолингвистические тенденции и изменения в регионе, произошедиие в течение последнего времени.
\end{abstract}

Ключевые слова: Италия, Сардиния, миноритарные языки, функции языка, идентичность, полевое исследование, сравнительно-сопоставительный подход

Ссылка при цитировании: Мажиа А. Языковая идентичность и языки идентичности (на примере острова Сардиния, Италия) // Вестник антропологии, 2021. № 3. C. 24-41.

\section{Языковая идентичность}

Нет необходимости оценивать степень важности той роли, которую язык играет в жизни каждой общности, представляя собой средство коммуникации и ее консолидации. Но одновременно он выполняет особую функцию в сфере коллективного

\footnotetext{
Мажиа, Армандо (Armando Махіа) - антрополог, директор Этнографического музея сардинской горской культуры (08031 Италия, Аритцо (провинция Нуоро), муниципальный парк «Пастиссу»). Эл. почта: maxiaarmando@tiscali.it. ORCID: https://orcid.org/0000-0002-2920-6921

*Статья написана автором на итальянском языке. Перевод на русский язык С.А. Сидневой
} 
сознания, что многократно отмечали исследователи (Edwards 2009; Edwards 1985, 1991, 1992, 1993; Fishman 1972; Gudykunst and Ting-Toomey 1990; Billig). Язык является формообразующим элементом идентичности и маркером самосознания ее представителей. Именно этими факторами обусловлено наше обращение к феномену сардинского языка, его современному состоянию и его эмическому видению населением, но наряду с этим - и тем обстоятельством, что позиции данного идиома в сардинском социуме в последние годы все более редуцируются, и из полноценного языка в недавнем прошлом он превращается в своего рода социолект, узус которого ограничен преимущественно домашней сферой.

В качестве рабочей гипотезы исследования принято наше предположение, что, вопреки оптимистическим утверждениям многих ученых, сардинский язык в настоящее время продолжает размываться и утрачивать активные позиции не только в городах и крупных центрах, но и в небольших населенных пунктах - объектах нашего исследования, где еще недавно господство сардинского языка было незыблемым, что масштаб социальной сферы его употребления резко сокращается и он сохраняется как средство полноценного общения только в очень ограниченной среде. Одновременно в исследовании представлены и подвергнуты анализу концепции сардинской идентичности и осмысливается взаимосвязь идентичности и языка, а также «пути» реализации первой через посредство локального идиома.

Данная статья основана в первую очередь на результатах нашего этнолингвистического исследования, проведенного в одном из районов «внутренней», горной Сардинии в 2019-2020 гг. В его ходе, путем опросов и включенного наблюдения, нами были получены и проанализированы материалы, освещающие уровень сохранения и применения родного языка местными жителями Сардинии в различных сферах их жизни. Помимо собственно полевого материала, нами использовались и резюмировались данные подробного социолингвистического обследования региона Сардиния, проведенного в 2007 г. университетами Кальяри и Сассари (Орро 2007), а также итоговые результаты мега-опроса по состоянию миноритарных языков и степени владения ими, проведенного Европейским Союзом в 1996 г. в различных европейских регионах, в том числе в Сардинии (Nelde, Strubell, Williams 1996). Собственно, сравнительно-сопоставительный подход с использованием этих данных и позволяет оценить культурные и социолингвистические тенденции и изменения в регионе, произошедшие в течение последних лет.

На первый взгляд полученные нами сведения кажутся несопоставимыми с более ранними материалами ни с формальной, ни с количественной точек зрения, поскольку они были получены вследствие обследования разных по охвату территорий и массивов опроса: пансардинское исследование Европейского Союза, равно как и проведенный университетами опрос имел общерегиональный масштаб и затрагивал как сельскую, так и городскую среду, тогда как наше исследование ограничивалось значительно более скромным ареалом, поскольку охватывало всего лишь небольшой район центральной горной области Барбаджа, а именно - Барбаджу-ди-Бельви и Барбаджу Мандролисай, в частности, деревни Аритцо, Бельви, Гадони, Меана, Тонара, Дезуло. Однако, забегая вперед, отметим, что, хотя собранные нами данные имеют отношение исключительно к сельской среде и небольшим поселениям, в которых проживает по несколько тысяч человек, они, похоже, вполне показательны и подтверждают рабочую гипотезу. 
Отметим особенности нашего метода работы, вытекающие из специфики объекта анализа. В ходе исследования мы прибегали преимущественно к интервью в свободной форме или к непринужденным, произвольным беседам с представителями разных социальных слоев при различных обстоятельствах и контекстах (а многие почерпнутые факты были и вовсе невольно подслушаны из чужих разговоров). Полученный материал является ценным, аутентичным и интересным с научной точки зрения, равно как и репрезентативным с точки зрения отображения тенденций современной социолингвистической реальности, хотя бы потому что позволяет взглянуть на нее с эмической позиции, то есть «изнутри».

Кроме того, проведение исследования в процессе обычной повседневной жизни совместной с респондентами, в ходе различных бытовых ситуаций, а также неформальный метод включенного наблюдения минимизирует риск отказа собеседников отвечать, а также позволяет избежать возможной формализации, условности и неестественности их ответов, которые могло бы вызвать применение формализованной анкеты, особенно в таком «закрытом» и традиционно ригидном регионе, как Сардиния и особенно ее горные районы.

Уместно в этой связи напомнить, что вся область Барбаджа в целом, особенно ее центральный горный массив исторически существует в режиме «интровертности», изоляции от центральной власти, и что бытование там до сих пор многих форм традиционности (норм обычного права, реликтов кровной мести, конфронтации локальной этики и этики государственной, отторжения всех форм внешнего «казенного» давления на население) неизбежно порождает недоверие к любому проявлению официальности, будь то опрос или полицейская проверка. Таким образом, использовавшийся нами с учетом локальных реалий исследовательский метод должен был оказаться и оказался более действенным и полезным при опросе больших групп населения, чем применение формализованного опросника или научных анкет, которые в соответствии и в контексте прошлого исторического опыта и стандартного мышления респондентов неизбежно ассоциируются у них, например, с полицейскими протоколами ${ }^{1}$.

Результаты социолингвистического исследования 2007 г. (Орро 2007), на которые мы опираемся, апеллируют к еще более раннему отчету 1996 г. о состоянии сардинского как идиома языкового меньшинства, в котором уже тогда звучала мысль, что в Сардинии «существует опасность вымирания языка» (Nelde, Strubell, Williams 1996: 17). При сравнении с его данными университетское социолингвистическое обследование 2007 г. подтверждает стремительное ухудшение фактического положения сардинского языка. Исследователями, в частности, отмечается, что сардинский язык в оценке его носителей почти полностью утратил сколь-либо существенную «престижность» и «значимость», а также - что он используется людьми не постоянно, а преимущественно ситуационно - например, в процессе совместного труда, на рабочих местах, а также в домашней обстановке. Но даже дома, в узком кругу, при общении друзей и родственников, на сардинском говорят в четко определенных контекстах и в достаточно ограниченных ситуациях - только при обсуждении очень

\footnotetext{
${ }^{1}$ Кроме того, как показал наш более ранний опыт работы, ответы опрашиваемых на «принудительные» вопросы формализованной анкеты чаще пронизаны неуверенностью и сомнением («я не знаю, прав ли я, но...»; «может быть, я ошибаюсь...»; «возможно, ты не согласишься ...»; «может случиться так, что я неправильно понял ...» и т.д.). С одной стороны, респондент, очевидно, пытается уйти от прямого, точного ответа, с другой - он как будто желает расположить к себе спрашивающего, ищет его одобрения и стремится оправдать его ожидания.
} 
личных, сугубо семейных проблем, на крестинах, свадьбах, похоронах.

Кроме того, респондентами констатировалось, что сардинский больше не продвигается органами публичной власти и образовательными учреждениями в той мере, в какой это происходило в течение короткого периода времени, охватывавшего 80-е и 90-е гг. ХХ в. В то десятилетие местные законы автономной области Сардиния предписывали популяризировать сардинский, преподавать его в школах и использовать в качестве официального языка в учреждениях (отметим, что лишь в единичных случаях эти законы получили практическую реализацию) (Marongiu 2019: 202). Также подчеркивалось, что на начало XXI в. сардинский язык практически выведен из официального употребления, и что он находится в состоянии упадка.

Еще более очевидным доказательством кризиса языка является тот факт, что даже те респонденты, которые утверждали, что хорошо им владеют, предпочитают не говорить на сардинском в присутственных и общественных местах. По заключению составителей итогового документа, «единственный положительный момент при оценке нынешнего состояния сардинского языка заключается в том, что его носители обеспокоены ситуацией с сардинским языком, так как сильно привязаны к нему на эмоциональном уровне и связывают его со своей идентичностью» (Орро 2007: 5).

Добавим, что в отчете 1996 г. (Nelde, Strubell, Williams 1996) утверждалось, что активно сардинский язык используют, в основном, пожилые мужчины, не имеющие высшего образования, принадлежащие к наименее привилегированным классам общества и проживающие в маленьких агрогородках и сельских населенных пунктах. Отмечалось, что подобное положение вещей обусловлено массовым распространением билингвизма и иерархичностью социально-лингвистической значимости отдельных языков Италии для населения. Итальянский язык интерпретировался как язык официального узуса, предназначенный для продвижения по карьерной лестнице и интеграции в общество; сардинский - как язык общения с определенной («своей») группой и идентификации с ней, осознанно служащий целям консолидации и декларирования внутригрупповой солидарности. Отмечалось также, что корреляция между языком и идентичностью начинает давать трещину, и что «обесценивание культуры» происходит из-за лингвистического обесценивания. В общем, результаты отчета 1996 г. о будущем сардинского языка уже были весьма неутешительны: представители Европейского Союза классифицировали его как язык, который «подлежит защите и требует помощи в развитии».

Более того, отмечалось, что аналогичные процессы касаются и остальных идиомов Сардинии: табаркино Карлофорте, имеющего лигурийское происхождение; каталанского Альгеро; турританского Сассари, относящегося к диалектам тосканской группы, и галлурского, представляющего собой корсиканский идиом. Как уже говорилось выше, исследование 2007 г. подтвердило эту тенденцию. Использование итальянского языка в общении с иностранцами или «чужими» становится общей нормой, а процент тех, кто обращается к местному идиому, уменьшается и имеет ярко выраженную социальную маркировку: как было сказано выше, речь идет о мужчинах с низкой квалификацией, занятых физическим трудом, в большинстве своем проживающих в небольших муниципалитетах.

В общественных заведениях и публичных местах (магазинах, барах, на рынках и т.д.) уже преимущественно используется итальянский язык. Его же все чаще выбирают при неформальном общении даже представители вышеуказанных категорий 
говорящих, если предполагается более ли менее общественный контекст. Наконец, в школе, церкви и в офисах именно итальянский используется как предпочтительный и более престижный лингвистический код. К сардинскому языку прибегают, когда нужно выразить сильные и неконтролируемые эмоции, как для одобрения, так и для угроз и брани, ярости или юмора. В этих случаях местный идиом имеет преимущество перед итальянским языком или используется вместо него. В других коммуникативных ситуациях, например, для поздравлений или соболезнований, все зависит от пола, и социального статуса говорящего, то есть сардинский будет использоваться все той же группой (мужчины, невысокий уровень образования, низший класс, ручная работа, небольшие сообщества и т. д.). Более четкой представляется картина в интроспективных или одиночных речевых актах, таких как размышление про себя и подсчет в уме, где предпочитаемым языком становится итальянский, в то время как мужчины с низким уровнем образования и рабочей квалификацией, преимущественно пожилого возраста, обращаются к местному языку, для которых он является первым.

Конечно, это общие тенденции, потому что реальное положение вещей требует более четких формулировок и предполагает большее разнообразие нюансов. У молодого поколения знакомство с местным языком происходит, как правило, в семье: ему учат родители, а самых младших - бабушки. Общение с товарищами и с одноклассниками играет важную роль в ситуации, когда нет возможности освоить местный язык в семье, т.к. дома все говорят по-итальянски. Лишь небольшое количество сардинцев (около 20\%) не знает сардинского языка, потому что в семье была сделана сознательная установка не говорить на «диалекте», который «малопригоден для жизни». При этом у большинства молодых двуязычных людей первым языком является итальянский. Юношей и девушек, выучивших в качестве первого языка местный его вариант, гораздо меньше и это всегда те, чьи родители говорят друг с другом на сардинском языке. При анализе социального статуса семей наблюдаются те же тенденции, что закономерны у старших поколений, то есть на сардинском языке говорят дети, родители которых имеют средний или низкий уровень образования и проживают в сельской местности, а не дети родителей с дипломами или учеными степенями, живущие в более-менее крупных городах. Следует также добавить, что детьми сардинский язык используется меньше, чем во взрослом мире, сфера его применения ограничена семьей, товарищами по играм и одноклассниками.

С одной стороны, позитивными тенденциями стоит считать заинтересованное восприятие языка самими носителями, что подтверждается и нашим исследованием. Широко распространена идея о том, что сардинский язык следует продвигать, потому что он является «важным и поддерживающим элементом нашей идентичности», или из-за его эстетической ценности, «потому что он красив», «музыкален», потому что это «древний язык» и т. д. Лишь меньшинство жителей Сардинии высказывает отрицательное суждение о нем. По их мнению, сформулированному М.Л. Вагнером, не стоит сохранять или оживлять этот «вымирающий» и «бедный язык пастухов и крестьян» (Paulis 1996: 30), потому что он «бесполезен для современной жизни», «неспособен выразить и передать всю сложность сегодняшней реальности» и т. д.

Контексты, в которых, как считается, следует благоприятствовать распространению языка, определяются чаще всего как семья и школа, в меньшей степени - как институциональная сфера, например, государственное управление. Здесь наблюдается антиномия между реальным поведением, переживаемым опытом и заявленными 
намерениями, «верой в язык». Фактически, более используемый языковой код, даже в контексте первой социализации, то есть в семейном кругу, - это итальянский язык, а, значит, позитивные суждения о ценности сардинского языка - дань некой ностальгии и способ самоубеждения. Еще больше вопросов и противодействий вызывает использование сардинского языка как вспомогательного вместо итальянского в школе для преподавания всех предметов, а не только истории. Такое отношение ясно показывает, как итальянский язык поддерживает свой статус языка «высокой культуры».

Исходя из этой сложной языковой картины можно сделать некоторые убедительные выводы. Очевидно, что сардинский язык находится в состоянии упадка и, кажется, все меньше используется даже в среде низших классов, в сельской местности, не говоря уже о более высокообразованном обществе (Mongili 2007: 84-85).

Этот феномен объясняется неравным статусом языков и их социального престижа. На самом деле у сардинского языка нет настоящего официального статуса: он не используется в школах или органами управления, церковью или политиками. Заметна в некоторой мере его дискриминация, т.к. только у итальянского языка есть высокий уровень престижа, тогда как сардинский занимает в иерархии социальных взаимоотношений ступень пониже: его роль - семейные и дружеские связи. Но и в этих сферах продолжается разрушительное воздействие итальянского языка, он уже доминирует в общении между супругами, а также между родителями и детьми. Это означает, что итальянский язык, то есть язык вторичной социализации (язык школ, контор, церкви, культурных организаций, собраний политических партий и т. д.), определенно вторгся в сферу первичной социализации и образования, отобрав у сардинского даже его роль языка общения в семье. Итальянский язык стал лингвистическим кодом «большего престижа и полезности», языком социальной мобильности. Престижный язык вызывает определенные ожидания в плане продвижения в иерархии общества, потому что его использование является маркером социального положения личности (Там же).

У сардинского языка настолько низкий социальный статус, что говорящий даже может подвергнуться стигматизации. Тенденция к использованию только итальянского языка в общении с детьми, которая наблюдается у более молодых родителей, показывает, насколько скомпрометированы механизмы передачи сардинского языка из поколения в поколение. Более того, противодействие использованию сардинского языка вместо итальянского для преподавания многих учебных предметов свидетельствует о желании сохранить сардинский язык лишь в качестве диалекта (Lupinu 2007: 96-97), чтобы в школе он играл только вспомогательную роль, по сравнению с итальянским. Запутанность языковой ситуации на Сардинии проявляется в противоречивом отношении большинства сардинцев к своему собственному языку, который они любят и воспринимают как идиому идентичности, но на самом деле считают диалектом, то есть, как бы рассматривают его как нечто вторичное и зависимое от итальянского языка.

Несмотря на данное противоречие или, возможно, именно из-за плохо скрываемого убеждения в его вторичности, сардинский язык большее число жителей знает и понимает, чем использует. В области его кодификации существует много теоретических размышлений, но так и не достигнуто единое стандартное решение для транскрипции. Сейчас этот язык находится скорее в фазе, когда высокий стиль используется чаще в неформальной и разговорной речи, чем в диглоссии. Этот язык жестко связан с определенным местом проживания и употребляется в функциональных сферах, определя- 
емых самими говорящими. Однако, благодаря некоторым манипуляциям с выстраиванием идентичности, неожиданно и, казалось бы, вопреки логике изложенных выше обстоятельств в настоящее время он признан одним из самых важных диакритических знаков идентичности сардинцев, одной из культурных черт, по которой они узнают друг друга и на основе которой конструируют понятие «свой».

Вместе с тем, ничего необычного в этом нет, поскольку в кажущемся противоречии на самом деле наиболее очевидно представлены все признаки сущности идентичности, которые складываются из «нарезок и сборных частей» или даже из «лохмотьев и заплат», как говорит Ф. Ремотти, «выдающих отсутствие органичности и связности, но скрытых с более или менее тонким искусством» (Remotti 2010: 22).

\section{Языки идентичности}

Еще одна цель нашего исследования - расшифровать механизмы авторепрезентации идентичности на Сардинии и, соответственно, выявить скрытые в ней функции. Теоретической основой анализа послужили идеи интерпретации культуры и идентичности Ж.-Л. Амзеля. Ученый противопоставляет «метисовскую логику» методу «этнологического разума», стремящегося классифицировать и каталогизировать такие категории, как этнические группы и культуры. В реальности это этнографические условности, которые часто рассматриваются как нечто исключительное и не связанное друг с другом.

Данному методу изучения отдельных элементов противопоставлен подход, который делает акцент на универсальности культур, на их «нечеткости или изначальном синкретизме» (Amselle 1999: 9-10), «смеси, которую сложно разложить на отдельные части» (Там же: 248), так как они связаны самыми настоящими неразрывными узами. Из этого можно сделать вывод, что понятия этноса, культуры и идентичности являются историческими категориями, то есть культурными конструктами или изобретениями. Если их внимательно проанализировать, раскроются любопытные процессы манипуляции, объективации и эссенциализации. То есть станет ясна условность понятий этнической принадлежности и идентичности, покажется иллюзорной идея классифицировать этнические группы как онтологически дифференцированные и несвязанные между собой единицы, а этническую идентичность как нечто четко очерченное и сложившееся (Fabietti 1995: 60-64; Remotti 2010: 36-37).

Результатом этого теоретического и эпистемологического переосмысления является вывод, что этнические группы больше нельзя рассматривать как замкнутые и противопоставленные один другому миры, и что этническая принадлежность является продуктом общественной договоренности различных групп, которые используют культурные различия, часто очень тонкие и почти незаметные, превращая их в неоспоримые этнические различия (Caltagirone 2000:16).

Такие манипуляции могут иметь разные цели и санкционируются то политической властью, то самими антропологами, которые не застрахованы от «придания плоти и крови» некоторым своим идеям (Там же: 16; Terray 1987: 19-31). Иногда же (как мы увидим позже) это практикуется внутри самих сообществ не без помощи местных интеллектуалов, у которых всегда есть свое видение местной идентичности. Подобные размышления порождают оксюморон, т.е. объект, который действует, но парадоксальным образом не существует, призрак, становящийся телом, или чем- 
то «подобным самому себе». Как это определяет Ф. Ремотти, имея в виду использование концепции идентичности, последняя постоянно «трактуется в признании ее функциональности, при этом мы действуем, исходя из того факта, что она действительно соответствует реальному объекту» (Remotti 2010: 34-36).

В данном исследовании предпринимается попытка обнажить механизмы искусственного конструирования идентичности, при помощи которого на Сардинии творцы этой идентичности скрывают «простое подобие самому себе» и превращают его в реальность (Там же; Remotti 1993: 113-124), таким образом объективизируя характеристики идентичности, которые ее внутренне структурируют: замкнутость, раздельность, определимость и, прежде всего, постоянство во времени. Особый интерес в данной связи представляют модули, с помощью которых идентичность ассимилируется с предметом, который по своему определению далек от переговоров, конкурентности имеющихся возможностей, и, в этом смысле, от постоянно надвигающихся рисков кризиса и исчезновения (Remotti 2010: 36).

Всюду, в том числе на Сардинии, понятие «идентичность» и обращение к корням стали актуальными в относительно недавнее время. Это произошло в 70-е и 80-е годы XX века, которые совпали с кризисом универсалистских или глобализационных перспектив. Именно на этом историческом этапе возник ряд требований политического характера: автономия острова и признание сардинцев в качестве особого культурно-языкового меньшинства (отчасти этому способствовала деятельность сардинских партий сепаратистского характера). Такие требования получили поддержку, а идея возвращения к истокам мотивировала, оправдала и облагородила претензии. Эксперименты, направленные на восстановление «сардинской идентичности, попираемой итальянскими колонизаторами» в 1970-х годах позволили достичь прочного консенсуса, который развился вокруг движений «Su populu sardu» и «Sardigna natzione». Более того, это период, когда гуманитарные и социальные науки начали заниматься темой идентичности, появились многочисленные публикации, сделавшие идентичность широко распространенной и вездесущей концепцией.

С этого момента идея взаимозависимости идентичности и языка проникает повсюду, без разбора распространяется на все идеологические установки, способствует всеобщему согласию и на Сардинии обретает нынешнюю устоявшуюся формулировку, которая защищается и ценится в региональных нормативных источниках.

Конечно, актуальность вопросов идентичности не связана с причинами местного характера: хорошо известна связь между глобализацией и поисками этнической идентичности. Отрицательные последствия глобальной экономики и политики требуют в рамках многих культурных, политических и научных традиций размышления над неизбежными проблемами, касающимися управления ресурсами. На Сардинии, например, встает вопрос о защите общественных инстанций, развития территориальных структур до такой степени, что даже проекты по охране окружающей среды, например, по созданию национального парка Дженнардженту, отвергаются сильной оппозицией, потому что они считаются препятствием для самобытной пастушеской традиции. В таких условиях требуется также переосмысление идентичности как ресурса, который в моменты кризиса может быть экономически выгодным «для развития туризма, последнего фатального миража сардинцев» (Caltagirone 2000: 116).

Устранить фикции идентичности обозначает определить поле социальных сил, которые разрабатывают концепцию идентичности, и выявить риторические приемы, 
применяемые для убеждения в ее реальности. Необходимо задаться вопросом, кто и для чего создает идентичность? Какими средствами? На какие сегменты общественной структуры осуществляется воздействие? Какие символы используются для этой цели? (Faeta 2005: 81).

Группа, которая занимается конструированием идентичности на Сардинии, - это некий союз интеллектуальных сил, которые разработали свое видение истории и культуры острова. Следует отметить, что объединившиеся вокруг них личности не сильно отличаются от интеллектуалов, которые, по замечанию Ф. Фаеты, пытаются создать местные идентичности для Юга Италии на материке (Там же: 81-85).

Будучи, в основном, представителями левых политических течений, они берут на себя миссию рупора для выражения общественного недовольства и сильного негодования по поводу ущемленных прав жителей, обращаются к реальным потребностям в коллективной идентификации. В числе их требований освобождение от воинской службы, развитие инфраструктуры (связи с полуостровом), официальное признание сардинского языка и его внедрение в школы, офисы и т. д. На самом деле, даже на Сардинии проблема идентичности не так уж волнует обездоленные группы населения (Там же). Гораздо чаще можно услышать об этом от учителя, государственного служащего, мелкого предпринимателя, артиста фольклорного ансамбля, исполняющего традиционные танцы или песни, которых хватает в каждой островной деревне.

Без этнографического и антропологического описания сардинских интеллектуалов картина будет неполной. Как правило, к этой группе принадлежат работники образовательной сферы, местного управления, профсоюзов, разнообразные любители фольклора или представители свободных профессий: журналисты, издатели, небольшие предприниматели, туроператоры и т.д. Они оказывают влияние на некую «боевую группу», распространителей их идей и прочих преданных последователей, которые имеют различное социальное происхождение и невысокий по сравнению с лидерами уровень образования. Этот фронт подпитывается, в основном, из своих же ресурсов: публикаций, посвященных острову, трудов исторической, этнографической и археологической направленности.

За редким исключением, местные интеллектуалы, как правило, далеки от академических кругов и не имеют адекватных концептуальных инструментов для интерпретации реальности и проблем, связанных с этносом и идентичностью. Их знания по антропологии и этнологии ограничиваются самыми известными работами итальянских исследователей, но они игнорируют иностранные тексты и новейшие теории, что также приводит к формированию местного (регионального) фольклорного видения мира, ностальгии по миру, который местные интеллектуалы, в сущности, никогда не знали по-настоящему. Часто они становятся привилегированными и немного самодовольными посредниками для передачи краеведческих знаний, народных традиций, лингвистических и исторических данных различным внешним наблюдателям, журналистам и даже ученым, которым они транслируют свой собственный подход к толкованию фактов. Справедливо будет упомянуть еще одно наблюдение Ф. Фаэты, пусть даже сформулированное для других этнографических контекстов. Исследователь заметил, что местные интеллектуалы не всегда соглашаются с пришлым антропологом. Они публично отмежевываются от него, щеголяя мелочами, которые ускользнули бы, с их точки зрения, от внешнего взгляда, но которые зачастую не оставляют следов в памяти непосредственных носителей традиции 
(Faeta 2005: 85). Хотя, с одной стороны, в этом видится доказательство их культурной ограниченности (Fabietti 1999: 107), все это красноречиво свидетельствует о типичном механизме конструирования идентичности, когда местная реальность формируется для собственного использования, а местная интеллигенция стремится стать ее эксклюзивным переводчиком.

Тот вариант идентичности, который представляют сегодняшние интеллектуалы Сардинии, чаще всего не опирается на конкретные данные, они больше склонны к теоретизированию, причем не всегда последовательному. Впрочем, последовательность не самое главное для идентичности. Ничто на Сардинии не выявляет наличие каких-либо биологических предрассудков вроде: одна и та же кровь, одна и та же группа. Уместно отметить, что строго биологизированные оппозиционные настроения, как правило, не являются ключевыми, можно сказать, их практически нет. (Geertz 1999: 88). То, что отличает сардинцев центральных областей от «меурреддос» Сульцис-Иглезиенте, - это этноним, с которым идентифицируются местные жители, предположительно берберского происхождения, мавританцы, изгнанные вандалами на Сардинию. Для их дифференциации важнее расстояния, а не биологический контекст. Исключительно важными могут стать и другие факторы, как мы увидим позднее.

Идентичность на Сардинии развивается в двух направлениях, показывающих нам всю сложность концепта этнической идентичности как таковой, в которой сосуществуют внутренние (эмические) и внешние (политические) аспекты: речь идет о сформулированных У. Фабиетти понятиях «переживаемой» и «показной» идентичности (Fabietti 1995:143).

Первая, «переживаемая» идентичность проистекает из практического контекста, совпадает с неявным, внутренним ощущением человека и чувством общности, о ней нет необходимости сознательно размышлять и как-то ее осмысливать в повседневной жизни. Элементарная человеческая сущность, как она определена Д. Анджони (Angioni 1998: 360), или своего рода «нулевая степень» идентичности, максимально обобщенная и простая (Caltagirone 2007: 30), первичная идентичность лишь изредка выражается в конкретных формулировках.

Вторая идентичность - показная, которая явно подчеркивается ее носителями в определенных контекстах. Фактически, она выбирает только отдельные детали, которые меняются от контекста к контексту и являются значимыми, потому что реагируют на ситуации оппозиционного и контрастирующего характера. Более того, эта идентичность находится в диалектических отношениях с идентичностью, навязанной извне (Fabietti 1995: 143).

Важно понять, как на Сардинии переживаемая идентичность, не являющаяся политическим конструктом или условной категорией, но формирующаяся в процессе социальной жизни, в которую погружен индивид, взаимодействует с показной идентичностью. В каких случаях? Как восприятие и местная репрезентация идентичности взаимодействуют с репрезентациями культурного и политического происхождения? (Лай 2007: 228-236).

В рамках данного исследования предпринята попытка выявить степень влияния интеллектуального дискурса в создании культурной памяти Сардинии через ориентализацию, экзотизацию, а также архаизацию традиций для доказательства их неизменности и длительности по времени. Подобные тенденции заметны в литературе, 
посвященной острову, начиная с XVII века. В частности, интересно наблюдать, как приписываемый извне характер принимается самими же этническими субъектами; как с этого момента саморепрезентация развивается в однозначно экзотическом направлении и используется для выстраивания особой идентичности. Прославление этой культурной архаичности и исключительности начал примерно в 1790 г. иезуит Маттео Мадао, опираясь на материалы XVI и XVII вв. Этот феномен создания мифического образа первородности и исконности также имел место позже в исследованиях Сардинии (Cirese 2006: 17).

В своей работе Маттео Мадао пытался доказать, что каждая традиция острова, от поэзии до танцев, от музыки до одежды, почти в нетронутом виде восходит к греко-римской античности или к самым отдаленным временам золотого века соседней восточной цивилизации. В том же духе иезуит Франческо Четти и тоже в конце XVIII в. писал, что «сардинские обычаи обнаруживают греческие и восточные черты во всех своих проявлениях: одежде, питании, нормах поведения, работе, празднествах и гостеприимстве» (Cetti 1774: 163). Продолжил линию М. Мадао и отец Антонио Брешиани, обратившись к убеждающей силе ораторского искусства. В названии своего труда он использовал такую риторическую фигуру, как пролепсис: «Об обычаях острова Сардиния в сравнении с обычаями древних восточных народов». Так автор сразу же заявил о своем видении сардинской культуры и выразил ключевую мысль повествования. На Сардинии, писал он, «как будто возвращаешься на тридцать веков назад, оказываешься то на Тигре и Евфрате, то на Иордане и Оронте, среди вавилонян, ассирийцев, финикийцев, армян и многих других народов, ранее всего населявших этот Восток» (Bresciani 1850: 69-70). С удивлением А. Брешиани восклицал, что обычаи здесь сохранились без изменений.

В 1869 году немецкий барон Генрих фон Мальзан так описал женский костюм из Аритцо: «У этих женщин самое мрачное на Сардинии платье <... Эти темные покровы отчасти напоминают одеяния африканских бедуинов, от которых и ведут родство жители Барбаджи» (Prunas Tola 1886: 373). И еще: «...Сардинские женщины, особенно в горных районах Барбаджи и Ольястры, предпочитают одеваться в платья, которые я назвал бы финикийскими, пеласгическими и эллинскими, за исключением некоторых элементов, возможно, принадлежащих самым первым жителям острова и чем-то похожих на то, что носили египтяне и вавилоняне» (Там же).

$\mathrm{B}$ первой половине XX века специалист по музыкальной этнографии, Джулио Фара, также развил миф о изначальности, автохтонности и неизменности во времени сардинской культуры. Для него традиционная сардинская музыка сохраняет почти полностью архаичные, доисторические черты, как в музыкальных мотивах, так и в инструментах (Cirese 2006: 17). В приведенном нами кратком списке приведены цитаты из самых известных работ. Но подобного рода идеи долгое время переходили из одних путевых заметок в другие, воспроизводились в разных компиляциях (Там же: 21), пока не стали парадигмой и авторитетным мнением, которые нужно учитывать, чтобы компетентно говорить об острове.

Можно согласиться с утверждением Клиффорда Гирца, что эти авторы «санкционировали» настоящую традицию письма и стратегии убеждения (Geertz 1990: 16), которые до середины XX века сильно влияли на местные хроники, сборники монографий, посвященные поселениям Сардинии. Именно этими источниками обычно пользовалась местная сардинская интеллигенция, работники муниципали- 
тетов, учителя начальных школ, наиболее образованные и начитанные врачи и мэры (Devilla 1885). В этом духе составлены отчеты местных приходских священников, книги об истории и происхождении деревень, их жителях и обычаях. Кроме того, подобные нарративы воздействовали на спонтанные формы первичной или переживаемой идентичности, которые, сформировавшись под этим влиянием, поддаются обобщению на более высоком уровне развития идентичности и культуры.

В 60-е годы XX века архаика уверенно заняла важную позицию в дискурсе идентичности. Это запустило механизм мифотворчества и заставило переписывать под него реальную историю (Asman 1997: 50-59).

Благодаря археологу Джованни Лиллиу нурагическому периоду ${ }^{\square}$ стало отводиться центральное место в коллективном воображении островитян (Lilliu 1963). Это положило конец модной с XIX века идее, согласно которой золотым веком Сардинии считались времена юдиката и Элеоноры Арборейской, создавшей «Carta de Logu» (сборник законов, направленных на регулирование правовой системы независимого сардинского государства) и защищавшей остров от испанских завоевателей. По мнению Лиллиу, именно нурагическая эпоха была образцом сардинской идентичности и свободы. Главный тезис теории исследователя - так называемая «константа сопротивления Сардинии» (Lilliu 1971). Согласно ученому, сардинское самосознание выстраивается вдоль непрерывной историко-этической и социальной линии, которая состоит в постоянном сопротивлении и антагонизме сардинцев по отношению к сменяющим друг друга завоевателям в долгой истории притеснений и внешних завоеваний. Эта интерпретация древней и современной истории Сардинии в духе конструирования «основополагающего мифа», которая получила широкое признание в различных культурных кругах, но слабость которой была продемонстрирована с помощью археологических данных (Madau 2001), по-прежнему является точкой отсчета при разработке «революционной мифодинамики» движений за независимость и при поисках идентичности.

Из этого мифа происходит и легенда о неукротимом сардинце (побежденном, но не сломленном), которая приписывает пастухам Барбаджи и даже бандитам гордый и мятежный дух древних пастухов-воинов нурагической эпохи из научных работ Лиллиу (Lilliu 1994: 19-22). Идея получила распространение и признание даже у тех сардинцев, кто далек от поисков идентичности и сепаратистских партий, она по-прежнему питает глубоко укоренившийся в народных массах общий дух. Следует отметить, что легенда имеет литературное происхождение, пусть даже ее создатель осознанно не ставил перед собой задачи продвигать какую-либо политическую идею или заниматься мифотворчеством. В своей поэзии Себастьяно Сатта, поэт-нуорец рубежа XIX и XX веков, воспевал жизнь внутренней пастушеской Сардинии, «суровых отцов», противостоящих легионерам, и «прекрасных, свирепых и храбрых» разбойников (Satta 1924: 39, 71).

С этого момента развернулось непрекращающееся мифотворчество, преобладающей стала риторика сардинской идентичности с подчеркнутой архаикой как доказательства автохтонности. Народные традиции Сардинии, выражение любого исторического состояния стало сводиться к концепции Этноса. Все оказалось этническим и потребовало этнологических объяснений: музыка, танец, стили одежды, поэзия и песни, выпечка хлеба, узоры на текстиле, резьба по дереву и прочие «древнейшие изделия». 
Именно в этой атмосфере родилась риторика «украденного прошлого», «наказания забвением» и «истинной» истории сардинцев, которая была перечеркнута очередными оккупантами и скрыта, чтобы сардинцы не осознали себя как этнос, имеющий свою собственную цивилизацию, и не освободились от колониального порабощения, в котором они в настоящее время живут. Авторами этой кампании по сокрытию «истинных исторических фактов», согласно данному подходу, является итальянское государство, которое навязывает соответствующие школьные программы, а также сама школа и, в частности, главное управление по охране объектов культурного и археологического наследия, академический мир и собственно творцы официальной историографии, скрывающие компрометирующие их доказательства, особенно когда те ставят под сомнение их теории.

Но официальную историю пытаются развенчать новые участники мифотворческого процесса и дилетанты (журналисты, какие-нибудь представители академической среды, ученые второго плана или работающие без привязки к какому-либо исследовательскому центру, археологи-самоучки и т.д.).

Список мифов, которые истолковываются как «скрываемая» официальными учеными история, довольно обширен: миф об Атлантиде, которую Серджио Фрау пытался отыскать на нурагической Сардинии (Frau 2002: 6); миф о шарданах, «людях моря», которых отождествляют с воинами нурагического периода; миф о башнях-нурагах как о храмах или древних обсерваториях или о донурагических мегалитических кругах с функцией астрономического календаря; всевозможные нарративы, приписывающие целительную силу памятникам нурагического и более древнего периода; недавние мифы о нурагической письменности (Cossu 2007: 123-124); миф о древней Сардинии, населенной племенем гигантов. В последней легенде как будто проявляется комплекс неполноценности из-за невысокого роста, которым всегда отличались сардинцы, а также используется типичный для мифотворчества механизм, строящийся на выделении какой-то исключительной черты.

Конечно, среди прочих не мог быть упущен миф о сардинском языке, так как язык - это наиболее яркое и непосредственное выражение идентичности и принадлежности к группе. Но группа сама должна осознать и выделить наиболее подходящие свойства, которые будут отличать ее от остальных. Они не могут быть заимствованы или навязаны извне, потому что в этом случае функция мифотворчества, необходимая для построения идентичности, окажется сильно дискредитированной. А процесс конструирования идентичности по-прежнему открывает неожиданные ресурсы и стратегии. Например, сардинский язык иногда рассматривается не как наиболее архаичный романский язык, происходящий от латыни, но выдвигаются теории о происхождении латыни от древнего сардинского языка. Вот так переосмысляется статус языка и поднимается его престиж.

Тенденция экзотизации и ориентализации проявляется и в том, что некоторые исследователи возводят нурагический язык к месопотамскому (Sardella 1991: 14-16), а «народ моря» - шардана, строители сардинских нурагов и «основатели» цивилизации нурагов, трактуются как выходцы из Шумерского царства.

Даже различные народные традиции переосмысляются в духе экзотики и абсолютной инаковости. Маскарады, связанные с карнавальным циклом, деликатная тема идентичности сардинцев, легко возводятся к архаичным дионисийским культам, хотя тип ряженых со звериными масками и в шкурах с коровьими колокольчиками встре- 
чается на довольно обширной территории от Средиземноморья до Балкан, от Альп до Скандинавии. Очевидна общая типология карнавала и его корней, поэтому местные традиции требуют более глубокого анализа. Подобные же упрощенные представления не без помощи средств массовой информации получили широкое распространение и в конечном итоге привели к созданию риторических условностей, которые в атмосфере «повторного открытия корней» спровоцировали «эксгумацию» местных звериных масок во многих сардинских деревушках и городках. Эти «древние маски» - по сути реконструкции, соответствующие заранее установленным моделям и санкционированные интеллектуалами-экспертами по дионисийским обрядам. Интеллектуалы контролируют разработку «правильных» символов идентичности, таким образом обреченных на то, чтобы стать «самореализующимся пророчеством».

«Живая простота», даже примитивность и исключительность черт сардинской идентичности теперь будут гарантированы не исторической отсталостью и культурной изоляцией, а гордым сознательным сопротивлением сардинцев влиянию извне, угрозе распада этнической группы и попыткам «лишения сардинцев общности» (Lilliu 1995: 9).

Здесь может показаться, что первичный или исключительный характер этнической группы определяется тем, что она «является категорией приписывания и идентификации со стороны самих агентов», как утверждает Фредерик Барт (Barth 1994: 34). Однако в понятии этничности в самом широком смысле и в строгом научном термине сохраняется некая семантическая двусмысленность, напоминая об общей культурной среде или общем наследственном происхождении (Stewart 1995: 318-319). Эта неопределенность, по-видимому, также касается понятий этнос и этническая идентичность, под которыми в контексте Сардинии имеются в виду не только культура и традиции, но также происхождение, родословная или кровное происхождение в физическом смысле, тех самых «суровых отцов» из поэзии Себастьяно Сатты.

Очевидный факт, что остатки эссенциализма присутствуют в сардинской риторике идентичности. Достаточно вспомнить их «расхожие и достаточно спекулятивные представления о том», что и сегодняшним сардинцам присуще «скругленное мышление» (сард. fiad in tundu puru su pensamentu), восходящее, как они считают, к способу мышления их древних предков (Lilliu 2004: 1), то есть идею о том, что ход мыслей местных жителей подчиняется преобладающей над всем концепции круговорота. При помощи забавного тезиса, согласно которому, «сардинцы мыслят кругами», сторонники теории этничности и идентичности пытаются доказать исключительность мыслительного процесса островитян.

Тем не менее, в таком конструировании сардинской идентичности нет ничего странного. Даже на этом острове «непостижимой архаичности» идентичность есть не что иное, как великий утешительный миф, который через механизм «разрезов и сборок» (Remotti 1996: 11) гарантирует свою обновляемость и при этом стабильность.

\section{Источники}

ПМА - Полевые материалы авторы. Данные опросов, проведенных в Сардинии (провинция Нуоро), 2019-2020 гг.

\section{Научная литература}

Amselle J.-L. Logiche meticce. Antropologia dell'identità in Africa e altrove. Torino: Bollati Boringhieri. 1999. 
Angioni G. L'identità come fatto e come valore // Le autonomie etniche e speciali in Italia e nell'Europa mediterranea. Processi storici e istituzioni. Cagliari: Consiglio Regionale della Sardegna. 1988. Pp. 359-365.

Assman J. La memoria culturale. Scrittura, ricordo e identitá politica nelle grandi civiltà antiche. Torino: Einaudi. 1997.

Barth F. I gruppi etnici e i loro confini // Maher V. (a cura di). Questioni di etnicità. Torino: Rosenberg e Seller. 1994. Pp. 33-71.

Bresciani A. Dei costumi dell'Isola di Sardegna comparati cogli antichissimi popoli orientali. Napoli: All'Uffizio della Civiltà cattolica. 1850. pp. XXV, IVI, 69-70.

Caltagirone B. Identità al confine. Il caso del Barigadu. Cagliari: Università degli studi di Cagliari. 2000.

Caltagirone B. Note preliminari a un rilevamento dell'identità in Sardegna // Angioni G. (a cura di). Sardegna; seminario sull'identità, Cagliari CUEC/ISRE. 2007. Pp. 29-35.

Cetti F. Storia naturale di Sardegna. Mattone A., Sanna P. (a cura di). Nuoro: Illiso. 2000.

Cirese A.- M. All'isola dei sardi. Nuoro: Il Maestrale. 2006.

Cossu T. Dall'identitá al passato: il caso della preistoria sarda// in Angioni G. (a cura di). Sardegna, seminario sull'identità. Cagliari: CUEC/ISRE. 2007.

Devilla G. L. La Barbagia e i barbaricini. Cagliari: Tipografia dell'Avvenire di Sardegna. 1885.

Fabietti U. L'identità etnica. Roma: La nuova Italia scientifica. 1995.

Fabietti U. Antropologia culturale. L'esperienza e l'interpretazione. Roma-Bari: Laterza. 1999.

Faeta F. Questioni italiane. Demologia, antropologia, critica culturale. Torino Bollati Boringhieri. 2005.

Frau S. Le colonne d'Ercole. Un'inchiesta. Roma: Nur Neon. 2002.

Geertz C. Opere e vita. L'antropologo come autore. Bologna: Il Mulino. 1990.

Geertz C. Mondo globale, mondi locali. Cultura e politica alla fine del ventesimo secolo, Bologna: Il Mulino. 1999.

Lai F. Per uno studio dell'identità in Sardegna: alcuni strumenti per la "cassetta degli attrezzi", in Angioni G. (a cura di). Sardegna; seminario sull'identità. Cagliari CUEC/ISRE. 2007. Pp. 226-237.

Lilliu G. La civiltà dei sardi dal Neolitico all'età dei nuraghi. Torino: ERI Edizioni RAI. 1963.

Lilliu G. Costante resistenziale sarda. Cagliari: Stef. 1971.

Lilliu G. L'eredità delle origini // Brigaglia M. (a cura di). La Sardegna. Enciclopedia. III. Aggiornamenti, Cronologie e Indici generali. Cagliari: Della Torre. 1994. Pp. 19-22.

Lilliu G. Una vita da archeologo. Sassari: Delfino.1995.

Lilliu G. Intervista su l’Unione Sarda. 10.03.2004. Pp.

Lupinu G. Alcune valutazioni sulla lingua // Oppo A/ (a cura di) Le lingue dei sardi. Una ricerca sociolinguistica. Cagliari: Universitá degli studi di Cagliari; Universitá degli studi di Sassari; Regione autonoma della Sardegna. 2007. Pp. 93-105.

Madau M. Alla ricerca dell'identitá perduta: il contributo dell'archeologia in Sardegna // Khanoussi M., Ruggeri P., Vismara C. (a cura di). L'Africa Romana. Lo spazio marittimo del mediterraneo occidentale. Geografia storica ed economica. Atti del XIV convegno di studio. Sassari, 7-10 Dicembre 2000. Roma: Carocci. 2001. Pp. 1085-1092.

Marongiu A. La situazione linguistica in Sardegna // Corsale A., Sistu G. Sardegna. Geografie di un'isola. Milano: Franco Angeli. 2019. Pp. 195-214.

Mongili A. Qualche approfondimento interpretativo// Oppo A. (a cura di) Le lingue dei sardi. Una ricerca sociolinguistica. Universitá degli studi di Cagliari; Universitá degli studi di Sassari; Regione autonoma della Sardegna. 2007. Pp. 83-94.

Nelde P., Strubell M., Williams G. (a cura di). Euromosaico. Produzione e riproduzione delle lingue minoritarie dell'UE. Bruxelles: Ufficio delle pubblicazioni ufficiali delle Comunità Europee. 1996. URL: http://www.uoc.es/euromosaic/web/ document/ sard/.

Oppo A. (a cura di). Le lingue dei sardi. Una ricerca sociolinguistica. Cagliari: Universitá degli studi di Cagliari; Universitá degli studi di Sassari; Regione autonoma della Sardegna. 2007.

Prunas Tola G. Il barone di Maltzan in Sardegna. Luogo: Alfredo Brigola e ...editore. 1886. 
Remotti F. Luoghi e corpi. Antropologia dello spazio, del tempo e del potere. Torino: Bollati Boringhieri. 1993.

Remotti F. Contro l'identità. Roma-Bari: Laterza. 1996.

Remotti F. L'ossessione identitaria, Laterza, Roma-Bari. 2010.

Sardella R. Il sistema linguistico della civiltà nuragica. Isili: Tipografia F.lli Ghiani. 1991.

Satta S. Canti del salto e della tanca. Cagliari: Il Nuraghe. 1924.

Sauzeau Boetti A.M. (a cura di). Dal museo al terreno. L'etnologia francese e italiana degli anni trenta. Milano: Angeli.1987.

Stewart M.S. Identitá sostanziale e identitá relazionale: gli zingari ungheresi sono un gruppo “etnico?// Piasere (a cura di). 1995.

Terray E. L'etnologia francese degli anni ‘30 e la situazione coloniale//In: Sauzeau Boetti A.M. (a cura di). Dal museo al terreno. L'etnologia francese e italiana degli anni trenta. Milano: Angeli. 1987.

Wagner M.L. La vita rustica della Sardegna riflessa nella lingua // Paulis G. Max Leopold Wagner e la Sardegna del primo Novecento. 1996.

Armando Maxia

\section{Linguistic Identity and Languages of Identity (the Example of Sardinia, Italy)}

DOI:

The study aims to decipher the mechanisms of self-representation by the inhabitants of Sardinia and, accordingly, to reveal the functions hidden in the concept of identity. Sardinian language is being the focus of special attention. The mechanisms of the artificial construction of identity are exposed through this idiom. The article presents current concepts and interpretations of the Sardinian identity and analyzes its relationship with the local language. The work is based on the results of an ethnological study conducted in one of the regions of inner Sardinia in 2019-2020. The material consists of interviews with Sardinians and the results of participant observation in their environment. The author also analyzes the state of the Sardinian language, its preservation, and how the island's population uses it in various spheres of life. The author compares the data obtained during his own field research with the two earlier studies.

Keywords: Italy, Sardinia, minority languages, language functions, identity, field research, comparative approach

For citation: Maxia, A. 2021. Linguistic Identity and Languages of Identity (on the Example of Sardinia, Italy). Herald of Anthropology (Vestnik Antropologii) 3: 24-41

Author Info: Maxia, Armando - Anthropologist, директор Этнографического музея сардинской горской культуры (08031 Italy, Aritco (Nuoro), Municipal Park "Pastissu"). E-mail: maxiaarmando@tiscali.it. ORCID: https://orcid.org/0000-0002-2920-6921

* Paper is written in Italian and translated into Russian by Svetlana Sidneva

\section{References}

Amselle, J.-L. 1999. Logiche meticce. Antropologia dell'identità in Africa e altrove [Half-breed logic. Anthropology of identity in Africa and elsewhere]. Torino: Bollati Boringhieri.

Angioni, G. 1988. L'identità come fatto e come valore [Identity as fact and as value]. In: Le autonomie etniche e speciali in Italia e nell'Europa mediterranea. Processi storici e istituzioni [Ethnic and special autonomies in Italy and in Mediterranean Europe. Historical processes and institutions], 359-365. Cagliari: Consiglio Regionale della Sardegna. 
Assman, J. 1997. La memoria culturale. Scrittura, ricordo e identitá politica nelle grandi civiltà antiche [Cultural memory. Writing, remembrance and political identity in the great ancient civilizations] Torino: Einaudi.

Barth, Fr. 1994. I gruppi etnici e i loro confini [Ethnic groups and their borders]. In: Maher V. (edited by). Maher V. (a cura di). Questioni di etnicitá [Questions of ethnicity], 33-71. Torino: Rosenberg e Sellier.

Bresciani, A. 1850.Dei costumi dell'Isola di Sardegna comparati cogli antichissimi popoli orientali [Of the customs of the island of Sardinia compared with the ancient Oriental peoples], XXV, ivi, 69-70. Napoli: Uffizio della Civiltà cattolica.

Caltagirone, B. 2000. Identità al confine. Il caso del Barigadu [Identity at the border. The case of Barigadu]. Cagliari: Università degli studi di Cagliari.

Caltagirone, B. 2007. Note preliminari a un rilevamento dell'identità in Sardegna [Preliminary notes to an identity survey in Sardinia]. In: Angioni G. (ed.). Sardegna: seminario sull'identità [Sardinia: Seminar on identity], 29-35. Cagliari: CUEC/ISRE.

Cetti, F. 2000. Storia naturale di Sardegna [Natural History of Sardinia]. Nuoro: Illiso.

Cirese, A.- M. 2006. All'isola dei sardi [To the island of Sardinia]. Nuoro: Il Maestrale.

Cossu, T. 2007. Dall'identitá al passato: il caso della preistoria sarda [From identity to the past: the case of Sardinian prehistory]. In Angioni G. (ed.). Sardegna, seminario sull'identità [Sardinia: Seminar on identity]. Cagliari: CUEC/ISRE.

Devilla, G.L. 1885.La Barbagia e i barbaricini [The Barbagia and the Barbaricinians]. Cagliari: Tipografia dell'Avvenire di Sardegna.

Fabietti U. L'identità etnica [Ethnic identity]. Roma: La nuova Italia scientifica. 1995.

Fabietti, U. 1999. Antropologia culturale. L'esperienza e l'interpretazione [Cultural anthropology. Experience and interpretation]. Roma-Bari: Laterza.

Faeta, F. 2005. Questioni italiane. Demologia, antropologia, critica culturale [Italian issues. Demology, anthropology, cultural criticism]. Torino: Bollati Boringhieri.

Frau, S. 2002. Le colonne d'Ercole. Un'inchiesta [The columns of Hercules. Investigation]. Roma: Nur Neon.

Geertz, C. 1990. Opere e vita. L'antropologo come autore [Works and life. The anthropologist as an author]. Bologna: Il Mulino.

Geertz, C. 1999. Mondo globale, mondi locali. Cultura e politica alla fine del ventesimo secolo [Global world, local worlds. Culture and Politics at the end of the twentieth century]. Bologna: Il Mulino.

Lai, F. 2007.Per uno studio dell'identità in Sardegna: alcuni strumenti per la "cassetta degli attrezzi" [For a study of identity in Sardinia: some tools for the " toolbox"]. In: Angioni G. (ed.). Sardegna; seminario sull'identità [Sardinia: Seminar on identity], 226-237. Cagliari CUEC/ISRE.

Lilliu, G. 1963. La civiltà dei sardi dal Neolitico all'età dei nuraghi [The civilization of the Sardinians from the Neolithic to the Nuragic age]. Torino: ERI Edizioni RAI.

Lilliu, G.1971. Costante resistenziale sarda [Sardinian resistive constant]. Cagliari: Stef.

Lilliu, G. 1994. L'eredità delle origini [The he5ritage of the origins], La Sardegna. Enciclopedia. III. Aggiornamenti, Cronologie e Indici generali [Sardinia. Encyclopedia. III. Updates, histories and general indexes], edited by M. Brigaglia, 19-22. Cagliari: Della Torre.

Lilliu, G. 1995. Una vita da archeologo [A life as an archaeologist]. Sassari: Delfino.

Lilliu, G. 2004. Intervista [Interview]. L”Unione Sarda.

Lilliu, G. 2012. Valorizziamo il nostro passato e saremo ricchi [Lets value our past and we will be rich]. Mameli G. Intervista [Interview]. La Nuova Sardegna 2.03.2012: 1.

Lupinu, G. 2007. Alcune valutazioni sulla lingua [Some evaluations on the language]. Le lingue dei sardi. Una ricerca sociolinguistica [The languages of the Sardinians. A sociolinguistic research], edited by A. Oppo, 93-105. Cagliari: Universitá degli studi di Cagliari; Universitá degli studi di Sassari; Regione autonoma della Sardegna.

Madau, M. 2001. Alla ricerca dell'identitá perduta: il contributo dell'archeologia in Sardegna [In search of lost identity: the contribution of Archaeology in Sardinia]. In: Khanoussi M., Ruggeri P., Vismara 
C. (ed.). L'Africa Romana. Lo spazio marittimo del mediterraneo occidentale. Geografia storica ed economica [The Roman Africa. The maritime space of the western Mediterranean. Historical and economic geography] (Atti del XIV convegno di studio. Sassari, 7-10 Dicembre 2000) [(Proceedings of the XIV study conference. Sassari, 7-10 December 2000)], 1085-1092. Roma: Carocci.

Marongiu, A. 2019. La situazione linguistica in Sardegna [The linguistic situation in Sardinia]. In: Corsale A., Sistu G. Sardegna. Geografie di un 'isola [Sardegna. Geographies of an island], 195-214. Milano: Franco Angeli.

Mongili, A. 2007. Qualche approfondimento interpretativo [Some interpretative deepening]. In: Oppo A. (ed.). Le lingue dei sardi. Una ricerca sociolinguistica [The languages of the Sardinians. A sociolinguistic research], 83-94. Cagliari: Universitá degli studi di Cagliari; Universitá degli studi di Sassari; Regione autonoma della Sardegna.

Nelde, P., M. Strubell, and G. Williams (ed.). 1996. Euromosaico. Produzione e riproduzione delle lingue minoritarie dell'UE. Bruxelles: Ufficio delle pubblicazioni ufficiali delle Comunità Europee [Euromosaic. Production and reproduction of EU minority languages. Brussels: Office for official publications of the European Communities]. http://www.uoc.es/euromosaic/web/ document/ sard/.

Oppo A. (ed.). 2007. Le lingue dei sardi. Una ricerca sociolinguistica [The languages of the Sardinians. A sociolinguistic research]. Cagliari: Universitá degli studi di Cagliari, Universitá degli studi di Sassari. Regione autonoma della Sardegna.

Paulis G. 1996. Saggio introduttivo [Introductory essay]. In: Wagner M. L. La vita rustica della Sardegna riflessa nella lingua [The rustic life of Sardinia reflected in the language]. Nuoro: Ilisso.

Piasere L. (ed.). 1995. Comunità girovaghe e comunità zingare [Wandering communities and gypsy communities]. Napoli: Liguori.

Prunas Tola G. 1886. Il barone di Maltzan in Sardegna [The Baron of Maltzan in Sardinia]. Milano: Alfredo Brigola e Co.

Remotti F. 1993. Luoghi e corpi. Antropologia dello spazio, del tempo e del potere [Places and bodies. Anthropology of space, time and power], 113-124. Torino: Bollati Boringhieri.

Remotti F. 1996. Contro l'identità [Against identity]. Roma-Bari: Laterza.

Remotti F. 2010. L'ossessione identitaria [Identity obsession]. Roma-Bari: Laterza.

Sardella R. 1991. Il sistema linguistico della civiltà nuragica [The language system of Nuragic civilization]. Isili: Tipografia F.lli Ghiani.

Satta S. 1924. Canti del salto e della tanca [Songs about the communal lands and about the enclosure], 39-71. Cagliari: Il Nuraghe.

Sauzeau Boetti A.M. (ed.). 1987. Dal museo al terreno. L'etnologia francese e italiana degli anni trenta [From the museum to the grounds. The French and Italian Ethnology of the Thirties]. Milano: Franco Angeli.

Stewart M.S. 1995. Identitá sostanziale e identitá relazionale: gli zingari ungheresi sono un gruppo etnico? [Substantial identity and relational identity: are Hungarian Gypsies an ethnic group?]. In Comunità girovaghe e comunità zingare [Wandering communities and gypsy communities], edited by L. Piasere, 318-319. Napoli: Liguori.

Terray E. 1987. L'etnologia francese degli anni '30 e la situazione coloniale [The French Ethnology of the 30s and the colonial situation]. In Dal museo al terreno. L'etnologia francese e italiana degli anni trenta [From the museum to the grounds. The French and Italian Ethnology of the Thirties], edited by A.M. Sauzeau Boetti, 19-31. Milano: Franco Angeli. 